\title{
EL CONTROL DE CONVENCIONALIDAD POR LOS JUECES Y TRIBUNALES ESPAÑOLES. A PROPÓSITO DE LA STC 140/2018, DE 20 DE DICIEMBRE
}

The Convencionality Control by Spanish Judges and Courts. About the STC 140/2018, of december $20^{\text {th }}$

\author{
MANUEL FONDEVILA MARÓN' ${ }^{1}$ \\ Universitat de Lleida \\ manuelfondevila@dpub.udl.cat
}

Cómo citar/Citation

Fondevila Marón, M. (2019).

El control de convencionalidad por los jueces y tribunales españoles: a propósito de la STC 140/2018, de 20 de diciembre. Anuario Iberoamericano de Justicia Constitucional, 23(2), 439-458. doi: https://doi.org/10.18042/cepc/aijc.23.13

\section{Resumen}

En el presente trabajo se analiza la posibilidad, consagrada en el FJ 6 de la STC 140/2018, de 20 de diciembre, de que los jueces ordinarios realicen el llamado con-

\footnotetext{
Manuel Fondevila es doctor europeo (con premio extraordinario) en Unión Europea por la Universidad Nacional de Educación a Distancia (2013) y doctor internacional (con premio extraordinario) en Derecho por la Universidade da Coruña. Actualmente es profesor lector Serra Hunter de Derecho Constitucional (acreditado como profesor agregado por AQU Catalunya y contratado doctor por ANECA) en la Universitat de Lleida y profesor tutor de Ciencia Política en el Centro Asociado de la UNED en Cervera. Ha sido profesor visitante en la Universidade Federal do Maranhão (noviembre 2015-marzo 2017) y en la Universidad Anáhuac de Xalapa (septiembre de 2017), y profesor y coordinador académico del Grado de Ciencias Políticas en la Universidad Internacional de La Rioja. Es autor de más de cincuenta publicaciones en editoriales y revistas indexadas de España, Brasil, México, Chile y Perú. Contacto: manuelfondevila@dpub.udl.cat / 973703238.
} 
trol de convencionalidad. Dado que es una materia bastante desconocida y sobre la que existe bastante resistencia por parte de jueces y tribunales, se hará un repaso sobre los debates teóricos y la práctica del mismo en nuestro país disertando, en concreto, sobre el reforzado papel de la jurisdicción ordinaria en la protección de los derechos fundamentales y si ello supone — como se ha dicho- un riesgo para el papel de la justicia constitucional o, más bien, todo lo contrario. Por último, se sacarán conclusiones de la práctica de este instrumento en el continente latinoamericano, de cara a su implantación completa en nuestro ordenamiento jurídico a todos los niveles.

\section{Palabras clave}

Control de convencionalidad; Justicia Constitucional; Derechos Fundamentales.

\section{Abstract}

This paper analyzes the possibility, enshrined in the 6th basis of STC 140/2018, of December 20, for ordinary judges to carry out the so-called conventionality control. Given that it is a matter quite unknown and on which there is a lot of resistance from judges and courts, a review will be made on the theoretical debates and the practice of it in our country, speaking, in particular, on the reinforced role of the ordinary jurisdiction in the protection of Fundamental Rights and if this implies - as has been said - a risk to the role of constitutional justice or, rather, the opposite. Finally, conclusions will be drawn from the practice of this instrument in the Latin American continent with a view to its full implementation at all levels in our legal system.

\section{Keywords}

Convencionality Control; Constitutional Justice; Fundamental Rights. 


\section{SUMARIO}

I. INTRODUCCIÓN: LA STC 140/2018, DE 20 DE DICIEMBRE DE 2018. II. ESTADO DE LA CUESTIÓN: EL DEBATE TEÓRICO Y LA PRÁCTICA DEL CONTROL DE CONVENCIONALIDAD EN ESPAÑA. III. CONSIDERACIONES SOBRE LOS TRIBUNALES CONSTITUCIONALES COMO JURISDICCIÓN DE LA LIBERTAD. IV. RETOS DEL EJERCICIO DEL CONTROL DE CONVENCIONALIDAD: LA EXPERIENCIA AMERICANA. V. REFLEXIÓN FINAL. BIBLIOGRAFÍA.

\section{INTRODUCCIÓN: LA STC 140/2018, DE 20 DE DICIEMBRE DE 2018}

La STC 140/2018, de 20 de diciembre, declaró la constitucionalidad de la LO 1/2014, de 13 de marzo, de modificación de la Ley Orgánica 6/1985, de 1 de julio, del Poder Judicial, relativa a la jurisdicción universal. Con la nueva redacción que esta ley otorga al art. 23 LOPJ se establecen nuevos requisitos de conexión, diversos para cada tipo de delito, para extender la competencia de los jueces y tribunales españoles más allá de nuestras fronteras, excluyendo, además, la denuncia como instrumento de activación del procedimiento penal y la acción popular prevista para estos supuestos.

A juicio de los recurrentes (cincuenta diputados del Grupo Parlamentario Socialista), se trataba de una ley regresiva, que atentaba contra los principios de interdicción de la arbitrariedad y de seguridad jurídica (art. 9.3 CE), y lesiva de los derechos al acceso a la jurisdicción (art. 24.1 CE) y a que ese acceso se garantizase, en condiciones de igualdad, a todos los ciudadanos españoles (art. $14 \mathrm{CE}$ ). Entendían, asimismo, que la ley orgánica impugnada vulneraba el art. 10.2 CE, por afectar al contenido de la jurisdicción universal que determinados tratados firmados y ratificados por España otorgan a esa noción. Adicionalmente, se estimaba que la ley violaba el art. $96 \mathrm{CE}$ por cuanto modificaba, sin seguir el procedimiento previsto en tal precepto, algunos tratados internacionales firmados por España que prevén la persecución universal de determinados delitos. La demanda identificaba en los nuevos arts. 23.2 b) y 23.6 LOPJ la lesión de los arts. 24.1, 124 y $125 \mathrm{CE}$, en la medida en que se suprimían la denuncia y la acción popular como instrumentos de inicio de un procedimiento penal en los casos de extensión extraterritorial de la 
jurisdicción. Y se imputaba, por último, a la disposición transitoria de la Ley Orgánica 1/2014 la vulneración del art. 117 CE, en su vertiente de exclusividad de la jurisdicción, en la medida en que la misma prevé el sobreseimiento provisional de los procedimientos incoados merced a la regulación previa de la extensión de jurisdicción.

En dicho procedimiento se personó la mesa del Congreso de los Diputados para responder a los reproches que la demanda hacía respecto del procedimiento legislativo seguido, indicando que consisten en un desacuerdo político sobre la forma de tramitación de la proposición de ley, que no cabe reconducir a causa de inconstitucionalidad alguna.

Por su parte, la Abogacía del Estado solicitó la desestimación de la demanda, negando la arbitrariedad y ausencia de seguridad jurídica en la nueva regulación, la desnaturalización de la jurisdicción universal y la contradicción entre la ley y el art. 10.2 CE. Descartó la lesión del derecho a la tutela judicial efectiva de las víctimas españolas, justificando las razones de la exclusión de la nacionalidad de la víctima como punto de conexión respecto de la persecución de determinados delitos, y rechazó la contradicción de la Ley Orgánica 1/2014 con el art. $96 \mathrm{CE}$, negando la premisa de que la nueva redacción del art. 23 LOPJ contrariase los tratados internacionales sobre la materia firmados por España. Rechaza también la denuncia de los vicios de inconstitucionalidad que el recurso atribuye a la nueva redacción de los arts. 23.2 b) y 23.6 LOPJ, al considerar justificadas las restricciones incluidas en estos preceptos respecto del ejercicio de la acción penal al referirse a la extensión extraterritorial de la jurisdicción, que es, en sí misma, una excepción al criterio general del principio de territorialidad. Por último, refutó la inconstitucionalidad de la disposición transitoria de la Ley Orgánica 1/2014, negando que infringiese el principio de exclusividad en el ejercicio de la jurisdicción que contempla el art. 117.3 CE y la interdicción de aplicación retroactiva de las normas restrictivas de derechos.

Tras una serie de consideraciones previas, el Tribunal concluye, en primer lugar, que se trata, ciertamente, de una ley que restringe el alcance del principio de jurisdicción universal respecto de la regulación anterior $(\mathrm{FJ} 4)$, pero que ello no contradice el art. 10.2 en relación con el 24.1 CE dado que los tratados no configuran un principio absoluto y general de jurisdicción universal que sea de obligada aplicación por los Estados (FJ 5). En segundo lugar, respecto de la vulneración del art. $96 \mathrm{CE}$, entiende que lo que los recurrentes solicitan es un control de convencionalidad de la norma por parte del Tribunal que queda fuera de sus competencias (FJ 6). En tercer lugar, afirma el Tribunal, que, aun cuando la nueva regulación pueda ser más gravosa para las víctimas, entra dentro de las facultades del legislador, puesto que esta no vulnera la seguridad jurídica ni resulta de criterios extravagantes, imprevisibles 
o discriminatorios (FJ 7), como también ocurre con la opción por suprimir la denuncia y la acción popular (FJ 8). Por último, se descarta la vulneración del art. 9.3 CE por no contener la regulación normas sancionadoras desfavorables ni restrictivas de derechos individuales (FJ 9).

La sentencia cuenta con el voto particular concurrente del magistrado Antonio Narváez Rodríguez, que discrepa de la argumentación mayoritaria en el FJ 5, pues entiende que los tratados sobre jurisdicción universal caen fuera del ámbito del art. 10.2 CE.

Como se puede observar, la resolución aborda dos cuestiones de gran trascendencia teórico-práctica. En primer lugar, el problema de la competencia extraterritorial de los juzgados y tribunales españoles para el conocimiento de determinados tipos de delitos, que es siempre una cuestión de enorme sensibilidad política ${ }^{2}$. En segundo lugar, la posibilidad de que los órganos jurisdiccionales de nuestro país ejerzan un control de convencionalidad de las leyes españolas, inaplicándolas cuando sean contrarias a tratados suscritos por España (una cuestión que ha generado un interesante debate doctrinal y que todavía suscita dudas y resistencias entre los órganos del Poder Judicial).

Dado que la primera de las cuestiones mencionadas ya ha sido abordada previamente por la jurisprudencia constitucional (STC 237/2005, sobre Guatemala $^{3}$ y ha sido, asimismo, más estudiada por la doctrina española ${ }^{4}$, en las siguientes páginas se analizará la segunda de ellas, pues se trata de un pronunciamiento novedoso y consagrador de este instrumento por parte del Tribunal.

Para el supremo custodio constitucional, el control de convencionalidad por los órganos jurisdiccionales ordinarios se reduce a una mera cuestión jerarquía normativa, ya que «el marco jurídico constitucional existente erige, pues, al control de convencionalidad en el sistema español en una mera regla de selección de derecho [sic] aplicable, que corresponde realizar, en cada caso concreto, a los jueces y magistrados de la jurisdicción ordinaria» (STC 140/2018, FJ 6), y solo a ellos, ya que:

[...] el análisis de convencionalidad que tiene cabida en nuestro ordenamiento constitucional no es un juicio de validez de la norma interna o de constitucionalidad mediata de la misma, sino un mero juicio de aplicabilidad de disposiciones normativas; de selección de derecho [sic] aplicable, que queda, en principio, extramuros de las competencias del Tribunal Constitucional que podrá, no obstante,

2 Las presiones de la República Popular China tuvieron su influencia en la decisión de restringir el alcance de la jurisdicción universal (Sanchez Legido, 2014: 6 y ss.).

3 Sobre esta sentencia, vid. Llobret Anglí, 2006.

4 Por todos, desde un punto de vista general teórico práctico, Chinchón Álvarez, 2014, y bibliografía allí citada. 
y en todo caso por la vía procesal que se pone a su alcance a través del recurso de amparo constitucional, revisar la selección del derecho [sic] formulada por los jueces ordinarios en determinadas circunstancias bajo el parámetro del artículo 24.1 $\mathrm{CE}$, que garantiza «que el fundamento de la decisión judicial sea la aplicación no arbitraria ni irrazonable de las normas que se consideren adecuadas al caso, pues tanto si la aplicación de la legalidad es fruto de un error patente con relevancia constitucional, como si fuere arbitraria, manifiestamente irrazonada o irrazonable no podría considerarse fundada en Derecho, dado que la aplicación de la legalidad sería tan sólo una mera apariencia» $(i b i d .)^{5}$.

Cabe preguntarse, y así lo ha hecho ya algún autor, si existe el riesgo de que la jurisdicción ordinaria arrincone, de este modo, a la jurisdicción constitucional en materia de protección de Derechos Fundamentales ${ }^{6}$. A lo largo de las siguientes páginas se tratará de demostrar, con argumentos teóricos y mediante el uso del Derecho Constitucional Comparado, que el control de convencionalidad resulta imprescindible en un sistema de justicia constitucional, por lo que el único riesgo para esta es la negativa que ha mostrado el Tribunal de hacerlo él también en el ejercicio del control de constitucionalidad.

\section{ESTADO DE LA CUESTIÓN: EL DEBATE TEÓRICO Y LA PRÁCTICA DEL CONTROL DE CONVENCIONALIDAD EN ESPAÑA}

El 1 de febrero de 2019 la asociación de Juezas y Jueces para la Democracia emitía un comunicado muy crítico con la sentencia comentada, sobre todo, por la tesis que la misma contiene respecto de la jurisdicción universal

5 Se añaden así dos matices a lo que — ante una alegación similar - el Tribunal Constitucional había establecido en el FJ 14 de la STC 49/1988 («Lo que se discute por los recurrentes es si el contenido de la Disposición adicional segunda es o no contrario a lo previsto en el Convenio, es decir la adecuación de una norma legal a lo preceptuado por el tratado, que tiene también fuerza de ley en el ordenamiento interior. Ahora bien, el examen de esa supuesta contradicción no corresponde a este Tribunal y no procede, por tanto, entrar en el fondo de este motivo alegado por los recurrentes, ya que no puede considerarse vulnerado el art. 96.1 de la Constitución»). En el mismo sentido SSTC 28/1991 (FJ5); 207/2013 (FJ4); y 270/2015 (FJ6).

6 De este modo lo formulaba el profesor Fernando Álvarez-Ossorio Micheo en una conferencia pronunciada el 2 de abril en el Centro de Estudios Políticos y Constitucionales (CEPC) titulada «Convencionalidad como constitucionalidad. La STC 140/2018, FJ 6, ¿un epitafio para el Tribunal Constitucional?». 
en relación con los Derechos Fundamentales ${ }^{7}$. Pero a renglón seguido —y por lo aquí interesa - valoraba también positivamente la novedad introducida en el FJ 6 de la sentencia, indicando al respecto: «[...] no negamos [...] que la sentencia pueda contener aspectos positivos porque de forma clara subraya que le corresponde al juez ordinario el llamado "control de la convencionalidad" de las normas». Con todo, se indicaba también:

[...] el «control de convencionalidad» es un tema no exento de complejidad, tradicionalmente objeto de muchas resistencias, y con una escasa extensión y comprensión en buena parte de nuestros jueces ordinarios. Esta realidad nos lleva a convenir en que no serán pocas las dificultades, al menos en las etapas iniciales de aplicación de esta jurisprudencia constitucional, para lograr la correcta aplicación del Derecho y alcanzar la justicia para las víctimas de los más graves crímenes internacionales.

A pesar de las dudas al respecto, el control de convencionalidad se ha venido ejerciendo en España, aunque de manera puntual. Ejemplo de ello es la Sentencia del Juzgado de lo Social n. ${ }^{\circ} 1$ de Tarragona de 2 de abril de 2014. En el FJ 7 de esta resolución, el juez inaplica el art. 4.3 EDL 3/2012 (período de prueba de un año) en virtud de lo dispuesto en el art. 4.4 de la Carta Social europea razonando que «de acuerdo con el principio de jerarquía establecido en el art. 9.3 de la Constitución Española, debe prevalecer la norma internacional que resulta de aplicación ${ }^{8}$. Pero, aparte de que los casos en los que la jurisdicción ordinaria ha ejercido el control de convencionalidad, prácticamente pueden contarse con los dedos de las manos, también es cierto que todavía pueden apreciarse muchas dudas y vacilaciones, confundiendo especialmente control de convencionalidad y de constitucionalidad, como demuestran algunos ejemplos de autos de tribunales superiores de justicia planteando cuestiones de inconstitucionalidad (vid. trabajo citado en nota supra) que cuentan con votos particulares de magistrados entendiendo que no resulta necesaria su remisión.

En el plano teórico la cuestión tampoco es que haya ha sido objeto de mucha atención. Sin embargo, durante esta última década se han publicado dos importantes obras que abordan esta cuestión con —además - dos tesis contrapuestas al respecto. El profesor L. Jimena (2013) lleva defendiendo desde hace más de una década que este control de convencionalidad sea realizado por los jueces ordinarios, como en el sistema americano de protección de derechos humanos. Se basa en lo dispuesto en los arts. 9.3, 10.2, 96 de la Constitución y en los arts. 5 y 6 de la Ley Orgánica del Poder Judicial. Para este autor, aunque

7 El texto completo del mismo está accesible aquí: https://bit.ly/346UTnF (acceso el 20 de agosto de 2019).

8 Más ejemplos en Salcedo Beltran, 2014. 
el TEDH no haya establecido expresamente esta obligación, la misma deriva de lo establecido en la Convención de Viena sobre el Derecho de los Tratados. El profesor R. Canosa (2015), por su parte, entiende inconveniente un control de convencionalidad difuso, y propone una reforma constitucional para que sea el supremo intérprete constitucional el que lleve a cabo el control concentrado de convencionalidad, excepto para una simple armonización — vía interpretación- de la normativa interna con la internacional.

\section{CONSIDERACIONES SOBRE LOS TRIBUNALES CONSTITUCIONALES COMO JURISDICCIÓN DE LA LIBERTAD}

Aunque el término «control de convencionalidad» y la práctica efectiva por parte de los jueces y tribunales sean — como se acaba de ver- relativamente recientes, la cuestión se había planteado y resuelto ya de modo teórico a principios del siglo xx. Para uno de los constitucionalistas más relevantes de este período: «[...] si la Constitución reconoce al Derecho internacional [sic] como parte integrante del Derecho nacional y si en ese país funciona la justicia constitucional, el conflicto entre la ley y el Tratado no puede tener más que una solución: la primacía del Tratado» (Mirkine-Guetzévitch, 2008: 298).

Aunque el constitucionalista ucraniano afincado en Francia se refería en la cita anterior a los Estados Unidos, su conclusión es perfectamente extrapolable al continente europeo en general y a España en particular. Dado que esta primacía de los tratados era reconocida en nuestro país tanto por la doctrina como por la jurisprudencia mucho antes de su positivización normativa en el art. 31 de la Ley 25/2014, la resistencia, por parte de los órganos judiciales, a llevarla a la práctica, inaplicando, en el caso concreto, la normativa nacional que los contradiga, solo puede proceder de una mala interpretación del llamado modelo concentrado de justicia constitucional, por entender, según la famosa máxima montesquiana, que el juez no puede ser más que la boca de la ley. Esta concepción está claro que lleva tiempo desfasada precisamente en el continente donde triunfaron las tesis kelsenianas acerca de la justicia constitucional, pues, como es de sobra conocido, el TJCE (hoy TJUE) estableció, en su célebre Sentencia Costa c. Enel, de 15 de julio de 1964, la obligación de los órganos judiciales nacionales europeos de dejar sin efecto cualquier ley contraria - anterior o posterior- a una norma de Derecho de la Unión Europea. Es decir: hace ya más de cincuenta años que los órganos judiciales estatales tienen la facultad de no aplicar, en determinados casos, normas con rango de ley y, actualmente, practican, de hecho, un verdadero control de convencionalidad respecto de la Carta de los Derechos Fundamentales de la Unión Europea (Nuevo, 2015). En el caso concreto de España, también los 
jueces ordinarios pueden inaplicar, por su sola autoridad, leyes preconstitucionales (STC 11/1981).

Adicionalmente, estudios recientes sobre justicia constitucional ponen de manifiesto que la dicotomía entre modelos difusos y modelos concentrados de justicia constitucional basada en la existencia de uno o más órganos llamados a ejercer el control de constitucionalidad resulta excesivamente simplificadora (Pegoraro, 2015: 46). El modelo difuso por excelencia (el estadounidense) presenta importantes elementos de concentración ya desde su propio origen, pero, sobre todo, tras las reformas procesales de 1988 que eliminaron su jurisdicción de apelación también respecto de los tribunales federales, pudiendo ahora discrecionalmente decidir sobre qué casos conocer. En Europa, además de que algunos países, como España, han incluido elementos de cierto control difuso (la cuestión de constitucionalidad), en Portugal existe un verdadero control difuso y un control concentrado en manos del Tribunal Constitucional.

De hecho, como se ha visto en la introducción, el Tribunal Constitucional se ha cuidado de considerar que el control de convencionalidad consistiese en un juicio por parte de los órganos de la jurisdicción ordinaria sobre la validez de las normas con rango de ley, y lo ha reducido a un mero conflicto de «ley aplicable», siendo el corolario de ello que el mismo queda fuera de sus atribuciones. Su conclusión, lamentablemente, demuestra también un claro desconocimiento de la teoría constitucional de la justicia constitucional concentrada. Precisamente el fundador de la Escuela de Viena se preguntaba jen 1925 ! si un tribunal constitucional debía anular una ley por ser contraria a un tratado internacional, y su respuesta era clara y contundente: cuando la Constitución reconoce al Derecho Internacional como parte del ordenamiento jurídico interno (independientemente de si le atribuye a los acuerdos internacionales naturaleza de ley constitucional o no), una ley contraria a un tratado es, por consiguiente - al menos indirectamente - inconstitucional. Afirma, de hecho, que «contra la anulación de las leyes ordinarias —o de los actos equivalentes o subordinados a estas leyes - contrarias a los Tratados no es posible esgrimir serias objeciones» (Kelsen, 1981: 186). En este caso —afirma-, la Constitución quiere que los tratados internacionales sean respetados por el legislador.

Es cierto que quien fuera presidente del Tribunal Constitucional austríaco sostiene - de manera discutible teniendo en cuenta lo que hoy establece el art. 27 de la Convención de Viena sobre el Derecho de los Tratadosla conclusión contraria cuando la Constitución no hace mención alguna al Derecho Internacional. Sea como fuere, está claro que no es el caso de la Constitución española a raíz de lo dispuesto en los arts. 10.2 y 96. Incluso sobre los tratados a los que se refiere el primero de estos preceptos el Tribunal 
Constitucional ha declarado que, aunque constituyen una fuente interpretativa (Castellà, 2000), ello no los convierte en canon autónomo de constitucionalidad (SSTC 64/1991, 373/1993 y 41/2002). Por consiguiente, se puede dar una declaración de inconstitucionalidad por vulneración de un precepto constitucional interpretado a la luz de un tratado internacional relativo a Derechos Humanos. Es el caso de la STC 236/2007, en la cual, en el FJ 6, el TC declara: «[...] esta regulación legal [el art. 7.1 L.O 4/2000] vulnera el art. 21 $\mathrm{CE}$ en su contenido constitucionalmente declarado por los textos a los que se refiere el art. 10.2 CE». No obstante, esto no ocurrirá con otro tipo de tratados ni cuando el contenido de estos no se corresponda con ningún derecho constitucional. De hecho, en la misma sentencia, FJ 11, el TC establece que «la Constitución no reconoce un derecho a la vida familiar en los mismos términos en que la jurisprudencia del Tribunal Europeo de Derechos Humanos ha interpretado el art. 8.1 CEDH, y menos aún un derecho fundamental a la reagrupación familiar, pues ninguno de dichos derechos forma parte del contenido del derecho a la intimidad familiar garantizado por el art. 18.1 CE», no viendo motivo, pues, de inconstitucionalidad en las remisiones reglamentarias contenidas en la citada ley.

Sin embargo, el supremo custodio constitucional, tal y como se vio, sí se arroga competencia para, en el marco de un procedimiento de amparo, revisar la selección de la ley aplicable realizada por el órgano jurisdiccional ordinario. Ejercería, de este modo, una suerte de control de convencionalidad a través de la concesión de un amparo por violación del art. 24.1 CE, si el juez o tribunal que dictaron la sentencia recurrida no aplicasen al caso concreto, de manera arbitraria, irrazonada o irrazonable, un tratado internacional en vigor. Es decir, que paradójica y, desde luego, contrariamente a la idea de modelo concentrado de justicia constitucional, el Tribunal no va a impedir que el legislador apruebe, a pesar de lo dispuesto en el 96.1 CE, una ley contraria a un tratado internacional, pero podrá en su caso conceder un amparo contra una resolución que aplique dicha norma. $\mathrm{Al}$ menos en una ocasión el TC ha procedido de este modo: en la STC 245/1991 (FJ 4) el TC afirmó que «la declaración de violación del art. 6.1 del Convenio, implica al mismo tiempo, de acuerdo a la cláusula del art. 10.2 C.E., una constatación de la existencia de una violación del derecho a un proceso público con todas las garantías del art. 24.2 CE», lo que ha llevado a pensar que, de la misma forma, sería posible declarar inconstitucional una ley por incumplir un tratado relativo a Derechos Humanos. Pero tanto, en este caso, como en el de la STC 236/2007, se trataría, más bien, de un control de constitucionalidad (López Guerra, 2019: 58).

Acaso pudiera pensarse que, en tanto que en el diseño teórico de Hans Kelsen los particulares no tenían acceso directo al Tribunal Constitucional, nuestro supremo custodio constitucional habría encontrado una solución ra- 
zonable y deferente para con el legislador, pero su modo de proceder le lleva a incurrir en no pocas contradicciones. Veamos dos ejemplos suficientemente ilustrativos. En primer lugar, se ha señalado ya en la introducción que el voto concurrente de esta Sentencia 140/2018 critica el modo de actuar del Tribunal en el fundamento jurídico 5, en donde (de modo similar a como hizo en la STC 236/2007) examina los acuerdos internacionales en materia de jurisdicción universal, a pesar de que los mismos no pueden considerarse, en rigor, dentro del marco de aplicación del art. 10.2 CE. En segundo lugar, en algunas ocasiones, como ocurre en la STC 11/2016, se dota de un nuevo contenido al art. 18.1 CE (referido a la «intimidad privada y familiar»), incluyendo dentro de este, y basándose en la jurisprudencia del TEDH sobre el más amplio «derecho a la vida privada y familiar» del art. $8 \mathrm{CEDH}$, el derecho de los padres a despedirse de los restos mortales de una criatura abortiva (la solución adoptada fue criticada por los votos particulares de los magistrados Francisco de los Cobos y Encarnación Roca Trías).

Una postura más acorde con la apertura internacionalista de nuestra Norma Fundamental, así como con el papel que debe jugar la justicia constitucional, implicaría incorporar los tratados al «bloque de constitucionalidad», de modo que una ley pudiera ser declarada inconstitucional por vulnerar cualquier tipo de convenio internacional, obligando, los específicos de Derechos Humanos, a interpretar los Derechos Fundamentales reconocidos en la Constitución de acuerdo con los mismos ${ }^{9}$. El TC español parece, por el contrario, seguir la «jurisprudencia IVG» (sobre la interrupción voluntaria del embarazo) del Consejo Constitucional francés, el cual también rechaza seguir estándares internacionales en el control de constitucionalidad, indicando que el control de la adecuación de la legislación nacional a los tratados ha de realizarse por la jurisdicción ordinaria (Jimena, 2019: 448).

Así pues, si acaso la jurisdicción ordinaria pudiera arrinconar al Tribunal Constitucional en materia de Derechos Fundamentales, no sería, pues, y como es lógico, porque esta lleve a cabo el ejercicio del control de convencionalidad que no solo — como se vio en el apartado anterior- la Constitución y las leyes, sino también — lo acabamos de ver- la justicia constitucional, le

9 Pocas constituciones reconocen expresamente - como lo hace la de Eslovenia (art. 160.1.2) — la facultad del Tribunal Constitucional de anular una ley por contraposición con un tratado. En algunas se deduce de sus disposiciones (en Holanda, se entiende que el art. 91.3 otorga a los tratados internacionales un rango superior al de la Constitución). En otros casos la Constitución otorga a los tratados internacionales en materia de derechos humanos rango constitucional, teniendo los demás rango infraconstitucional (vid., a modo de ejemplo, el art. 50.3 de la Constitución de Austria, el 93 de la Constitución de Colombia o el art. 75.22 de la Constitución de Argentina). 
imponen, como por este ejercicio de dejación de funciones por parte del Alto Tribunal. Negarse, como sugería Kelsen, a declarar la inconstitucionalidad de una norma por violación indirecta de la Constitución por ser esta contraria a un precepto constitucional, puede muy bien generar la impresión de que el Tribunal Constitucional resulta una instancia menos protectora de los derechos de los ciudadanos que los jueces y tribunales ordinarios. Buen ejemplo de ello lo constituye la STC 119/2014, en donde, por negarse el Tribunal, tal y como critica el voto particular del magistrado Fernando Valdés Dal-Re (ponente de la STC 140/2018 que aquí comentamos), y a quien se adhieren la magistrada Adela Asúa Batarrita y el magistrado Luis Ignacio Ortega Álvarez, a aplicar los estándares internacionales relativos a la protección del derecho del trabajo, se declara constitucional el artículo del RDL 3/2012, que se ha visto que había sido inaplicado por varios órganos jurisdiccionales ordinarios. Lógicamente, nada impide — desde un punto de vista técnico- que una ley declarada constitucional por el Tribunal Constitucional (y, por lo tanto, válida) quede supeditada en su aplicación (por lo tanto, en su eficacia) a una norma internacional que prevalece (art. 31 de la Ley 25/2014), pero está claro que ello puede derivar en un aumento de la litigiosidad.

Debe recordarse, además, que la reforma operada en el recurso de amparo por la LO 6/2007 y los requisitos establecidos por la jurisprudencia constitucional (STC 155/2009) hacen tan poco plausibles las posibilidades de que un recurso de amparo sea, si quiera, admitido a trámite, que algún autor incluso se ha preguntado si este tiene algo que ver, en su configuración actual, con el remedio contra violaciones de derechos fundamentales ideado por el constituyente de 1978 (Tenorio, 2018).

No es este, como es lógico, el lugar oportuno para dirimir ni si la reforma era o no necesaria ante la situación de colapso que llegó a vivirse en el Tribunal Constitucional (en 2006 se presentaron ante el Tribunal Constitucional 11471 recursos de amparo), ni tampoco si ha resultado eficaz a la luz de los datos actuales (6287 recursos planteados en 2017, pero con un porcentaje de éxito todavía no superior al $2 \%$ ). Lo que, por el contrario, interesa, de cara a poder realizar alguna aportación al debate que se ha venido planteando, es concluir este apartado con una serie de reflexiones acerca del papel de la jurisdicción ordinaria y del Tribunal Constitucional en la protección de los derechos fundamentales.

El juicio de amparo es una creación original del constitucionalismo mexicano del siglo xIX, pudiendo ser considerado padre intelectual del mismo Mariano Otero. Ahora bien, este nada tiene que ver con nuestro recurso de amparo constitucional establecido en la Constitución de 1978, inspirado directamente en la verfassungsbechwerde alemana, establecida primero por vía legislativa y después mediante reforma constitucional en 1969. Solo en unos 
pocos Estados europeos, además de España y Alemania (concretamente en Croacia, Eslovaquia, Eslovenia, Hungría, Polonia y República Checa), los particulares tienen acceso directo al Tribunal Constitucional.

Pero que exista la posibilidad no significa que no sea en los juzgados y tribunales ordinarios donde, con carácter preferente, debe ponerse remedio a las presuntas violaciones de Derechos Fundamentales. Ello es así porque el recurso de amparo convierte al Tribunal Constitucional en una suerte de tribunal de «supercasación», constituyendo, como ha señalado —en contra del parecer mayoritario en la doctrina española- el profesor De Vega (2002: 702), un «recurso de los desesperados». De hecho, el propio Tribunal Constitucional reconoce que debe ser en la jurisdicción ordinaria donde los particulares logren reparar eventuales lesiones de sus Derechos Fundamentales (por todas, STC 147/1994), pudiendo hacerlos valer en ese nivel también frente a violaciones producidas por particulares.

Las razones históricas por las que la Constitución española de 1978 decidió establecer el recurso de amparo constitucional ${ }^{10}$ (unos integrantes del Poder Judicial que se habían formado y hecho la carrera en el franquismo) resultan muy comprensibles, y nadie negará tampoco la enorme aportación a la dogmática de los Derechos Fundamentales que a través de la resolución de los recursos de amparo ha llevado a cabo el Tribunal. Pero no se debe olvidar, tampoco, que porque la Constitución es una norma interpretable por todos los operadores jurídicos (incluidos, por supuesto, los órganos jurisdiccionales ordinarios), un tribunal constitucional debe, en la medida de lo posible, abstenerse de imponer una única interpretación posible de los derechos reconocidos en la Constitución (Bustos Gilbert, 1999: 289). De hecho, son también este tipo de resoluciones las que han provocado lamentables enfrentamientos con el Tribunal Supremo (Matia Portilla, 2016).

\section{RETOS DEL EJERCICIO DEL CONTROL DE CONVENCIONALIDAD: LA EXPERIENCIA AMERICANA}

Como bien indica nuestro supremo intérprete constitucional en el FJ 6 de la sentencia que estamos comentando, el concepto de control de convencionalidad surgió en el ámbito de la Convención Americana sobre Derechos Humanos. En concreto, en la bien conocida Sentencia Almonacid Arellano y otros vs. Gobierno de Chile, de 2006, la CIDH indicó que «cuando un Estado

10 En sede constituyente, algunos senadores, como Martín Retortillo, Azcárate y Angulo, mostraron sus dudas sobre la idoneidad de establecer dicho instrumento. 
ha ratificado un Tratado internacional como la Convención Americana, sus jueces, como parte del aparato del Estado, también están sometidos a ella, lo que les obliga a velar porque los efectos de las disposiciones de la Convención no se vean mermadas por la aplicación de leyes contrarias a su objeto y fin, y que desde un inicio carecen de efectos jurídicos», aunque matizaba en Trabajadores cesados del Congreso vs. Perú que ello «tampoco implica que ese control deba ejercerse siempre, sin considerar otros presupuestos formales y materiales de admisibilidad y procedencia de ese tipo de acciones».

Estas resoluciones vinieron a consagrar una evolución jurisprudencial por parte de la Corte consistente en confrontar la Convención con la normativa nacional. En los casos Loayza Tamayo versus Perú (1997) o Suárez Rosero versus Ecuador (1997) la Corte había considerado ciertas normativas internas como contrarias a la Convención, pero sin indicar claramente que deban ser anuladas. En los casos de «La última tentación de Cristo» (Olmedo y Bustos contra Chile, 2001) y Barrios Altos versus Perú (2001) reconocía ya que las normas internas que evitan la aplicación de la Convención no podían constituir un obstáculo a la eficacia del tratado. Por lo que respecta, en concreto, a la expresión "control de convencionalidad», aparece por primera vez en el voto concurrente del juez García Ramírez en el caso Myrna Mack Chang versus Guatemala (2003).

La evolución reciente de este control de convencionalidad consiste en el paso de un control puramente «represivo» a uno "constructivo» (Sagüés, 2014), que obliga a adaptar, tanto por parte del Poder Judicial como por Parte del Legislativo, toda normativa nacional a las disposiciones de la Corte ${ }^{11}$.

En este continente, además, los tribunales constitucionales y cortes supremas han incorporado, por lo general, al menos los tratados en materia de Derechos Humanos al «bloque de constitucionalidad», y convertido, por tanto, a estos, en parámetro de constitucionalidad de las leyes, con reticencias en algún caso, como el chileno (Nogueira, 2012). Además, esto es así tanto en los sistemas de justicia constitucional, en los que se concentra en un solo órgano, la competencia de llevar a cabo el control de constitucionalidad (Costa Rica), como en aquellos sistemas donde cada juez puede llevarlo a cabo (Argentina, Bolivia, Colombia, Ecuador, El Salvador, Guatemala, México, Perú, República Dominicana).

11 En Radilla Pacheco vs México la Corte indica que «es necesario que las interpretaciones constitucionales y legislativas se adecuen a los principios establecidos en la jurisprudencia de este Tribunal» (\$340). Tesis que se repite en Cabrera García y Montiel Flores vs. México. 
La experiencia del continente latinoamericano confirma nuestra hipótesis de que el control de convencionalidad, lejos de debilitar, refuerza la jurisdicción constitucional. En concreto, se ha observado un "diálogo bidireccional» (Ayala, 2013: 160 y ss.) en el que, del mismo modo que los altos tribunales y cortes constitucionales nacionales recogen la jurisprudencia de la $\mathrm{CIDH}$, este también utiliza y cita la jurisprudencia de aquellos ${ }^{12}$.

En todo caso, y como es obvio, que el concepto de control de convencionalidad se haya desarrollado en el ámbito del Derecho Internacional regional de Derechos Humanos en el continente americano no quiere decir que solo estos instrumentos puedan servir de parámetro para el enjuiciamiento de las leyes. Tal y como se ha visto, el control de convencionalidad se ha venido practicando, sobre todo, en el ámbito de los derechos sociales, contrastando la normativa y la jurisprudencia nacional con textos como la CEDS, el Convenio de la OIT, etc. Así pues, del modo en que ha sido formulado, este control de convencionalidad "constructivo» o "preventivo» (porque opera antes de que el Poder Judicial repare una eventual lesión) consistiría en una suerte de «voluntad constitucional» (Ruipérez, 2017: 293) por parte de creadores y operadores jurídicos de cumplir con los mandatos de los tratados internacionales — por ser también esta la voluntad del constituyente-, sirviendo para realizar avances en el ámbito social.

Ahora bien, aunque la doctrina mayoritaria en Latinoamérica ha acogido con entusiasmo la doctrina del control de convencionalidad, también algunas voces se han mostrado críticas con algunos excesos que la misma puede contener. Se ha criticado, en concreto, el modo mecánico en el que la Corte pretende que se aplique el control de convencionalidad, y se ha sugerido un mayor respeto al «margen de apreciación nacional» como técnica del self restraint por parte de la Corte (Colombo, 2019).

En el continente europeo, por su parte, el TEDH no ha derivado del art. 1 del CEDH una obligación similar para los jueces nacionales de colaborar con él en la vigilancia de los tratados, tendiéndose a un control concentrado de convencionalidad a través de las «sentencia piloto» (Queralt, 2018: 399) y el protocolo n. ${ }^{\circ} 16$ anexo a dicho convenio (en vigor desde el 1 de agosto de 2018), que permite a los altos tribunales de los Estados parte del Consejo de Europa formular opiniones consultivas, y que, no obstante, no ha sido firmado ni ratificado por España ni parece que lo vaya a ser en un futuro próximo ${ }^{13}$.

12 Vid., a modo de ejemplo, Chocron Chocron vs. Venezuela, de 1 de julio de 2011, o Gelman vs Uruguay, de 24 de febrero de 2011.

13 Así lo informa la página web del Ministerio de Justicia: https://bit.ly/2r7ptyW (acceso el 22 de agosto de 2019). 
Dado que, como se ha dicho, esta obligación deriva, en todo caso, de la Convención de Viena sobre el Derecho de los Tratados y de las propias Constituciones, más que un inconveniente podría constituir una oportunidad, para este continente, de implementarlo sin los problemas para algunas tradiciones constitucionales que se han apreciado al otro lado del océano.

Pero, probablemente, el mayor reto en Europa sería conciliar el control de constitucionalidad, el de convencionalidad y la primacía del Derecho de la Unión Europea. Los avances, sobre todo, jurisprudenciales, en la dirección de la construcción de un sistema integrado de Derechos Fundamentales permiten resolver la cuestión de un modo relativamente sencillo cuando el juez ordinario tiene claras las pautas de actuación, distinguiendo si estamos ante un supuesto o no de aplicación del Derecho de la Unión Europea (Fondevila, 2017: 356).

El juez debe, en primer lugar, llevar a cabo el control de convencionalidad, pues si la norma es contraria a los tratados internacionales no puede ser aplicada. Si nos encontramos frente a un juicio de Derechos Humanos hay un matiz importante en el caso de que estemos ante un supuesto de aplicación del derecho de la Unión Europea: según la jurisprudencia del TEDH establecida en el caso Bosphorus Hava Yollari Turizm ve Ticaret Anonim Sirketi contra Irlanda, de 30 de junio de 2005, el Derecho de la Unión Europea se presume conforme al CEDH. Esto condiciona este primer examen realizado por el juez, pero no se debe olvidar que se trata de una presunción iuris tantum. En el caso de los demás tratados internacionales se impone la primacía del Derecho de la Unión Europea (con la posibilidad o, en su caso - y de acuerdo con el art. 267 TFUE—, obligación de plantear al TJUE la cuestión prejudicial), al que bien, ya de un modo implícito, como la Constitución española (art. 93 CE) o la italiana, ya explícitamente, mediante una cláusula específica de integración (Letonia, Eslovaquia, Francia, Portugal, Hungría, Alemania y Suecia), las constituciones de los Estados miembros reservan un papel más relevante que el del Derecho Internacional general, por lo que se vería desplazado en su aplicación.

Una vez realizado este examen, todavía le queda al juez llevar a cabo el control de constitucionalidad, que en el caso de España se traduce en aplicar la norma conforme, en su caso, a los tratados (juicio positivo de constitucionalidad), o en el planteamiento de la cuestión de inconstitucionalidad (si el juicio sobre la constitucionalidad de la norma es negativo). Debe hacerse en este orden para poder complementar el control de convencionalidad y de constitucionalidad, en el sentido de poder interpretar la Constitución de acuerdo con la norma internacional, cuando ello sea posible. En caso de encontrarnos ante un supuesto de aplicación del Derecho de la Unión Europea, la última jurisprudencia al respecto del TJUE (Aziz Melki, asunto C-188/10) 
permite al juez nacional plantear la cuestión prejudicial y ejercer las demás facultades que le asisten como juez de la Unión Europea (inaplicar la norma nacional contraria al derecho de la UE o adoptar medidas cautelares) tanto antes, al tiempo, o después de haberse remitido la cuestión de inconstitucionalidad. Ello es algo que corresponde regular al Derecho Procesal Constitucional interno. En el caso de España, el Tribunal Constitucional —en el ATC 168/2016 - ha indicado que no cabe el planteamiento simultáneo de ambos incidentes, y que los arts. 163 CE y 35 LOTC exigen el planteamiento previo de la cuestión prejudicial, de cara a establecer claramente que la norma de cuya compatibilidad con la Constitución se duda resulta de aplicación por ser compatible con el Derecho de la Unión.

Además, el Tribunal Constitucional, a través de la resolución de un recurso de amparo, puede siempre poner coto a eventuales excesos por parte del Derecho de la Unión aplicando, del modo que han hecho otros homónimos europeos, la teoría de los contralímites ${ }^{14}$. Esta posibilidad debe quedar siempre abierta — tal y como el TC ha precisado en el FJ 4 de la DTC 1/2004en virtud del principio de supremacía constitucional, si bien reservada para casos absolutamente excepcionales.

\section{REFLEXIÓN FINAL}

Llevar a cabo el control de convencionalidad es una exigencia para todos los órganos de un Estado para evitar incurrir en responsabilidad por ilícito internacional (Bazán, 2015: 28 y ss.) y más concretamente de todo Estado de Derecho en donde funcione la justicia constitucional. Dos ejemplos de Estados europeos ayudarán a verificar — a sensu contrario — estas afirmaciones. En Gran Bretaña (donde no existe, control jurisdiccional de constitucionalidad) la Human Rights Act (sec. 4) permite a un órgano judicial declarar la incompatibilidad de una norma con el CEDH («control de compatibilidad») pero sin afectar a su validez ni eficacia (Carmona, 2011:59). Por otra parte, en Francia, el otro Estado europeo donde, hasta 2008, no existía más que un control político de constitucionalidad, los tribunales ordinarios vinieron supliendo esta carencia de justicia constitucional mediante el control de convencionalidad, con base en lo dispuesto en el art. 55 de su Constitución.

El control de convencionalidad amplía las facultades de los jueces ordinarios en los sistemas de justicia constitucional concentrada, aunque pueden,

14 Caso Taricco, relativo a Italia: STJUE de 5 de diciembre de 2017 y SCC 115/2018, de 10 de abril. 
en contrapartida, ver limitadas sus facultades interpretativas por la jurisprudencia constitucional e internacional que sea de aplicación (Sagüés, 2011: 149). Igualmente para el órgano que, en un sistema de justicia constitucional concentrado ejerce el monopolio del control de constitucionalidad, el control de convencionalidad resulta de obligado ejercicio por imposición constitucional.

Con base en todo lo expuesto, la afirmación realizada por el Tribunal Constitucional español en la STC 140/2018, FJ 6, merece, de un lado, un juicio positivo por despejar las dudas acerca de la obligatoriedad de ejercer este control de convencionalidad a nivel de la jurisdicción ordinaria, pero, por otro lado, resulta criticable por cuanto que excluye la posibilidad de ejercer él mismo dicho control.

\section{Bibliografía}

Ayala Corao, C. (2013). Del diálogo jurisprudencial al control de convencionalidad. México: Porrúa.

Bazán, V. (2015). El control de convencionalidad como instrumento para proteger derechos esenciales y prevenir la responsabilidad internacional del Estado. Anuario Iberoamericano de Justicia Constitucional, 19, 25-70. Disponible en: https://bit.ly/2NPE2Pf.

Bustos Gilbert, R. (1999). ¿Está agotado el modelo de recurso de amparo diseñado en la Constitución española? Teoría y Realidad Constitucional, 4, 273-292. Disponible en: https://bit.ly/2NqsjHP.

Canosa Usera, R. (2015). El control de convencionalidad. Navarra: Thompson Reuters.

Carmona, W. F. (2011). La diferenciación entre control de constitucionalidad, control de convencionalidad y control de compatibilidad. Anuario Iberoamericano de Justicia Constitucional, 15, 51-66. Disponible en: https://bit.ly/36Ow55I.

Castellà Andreu, J. M. (2000). La Declaración Universal de Derechos Humanos y los convenios internacionales ratificados por España en materia de Derechos Humanos. El art. 10.2 de la Constitución española. En G. Piturzzella, F. Teresi y G. Verde. Il ruolo del parámetro nella classificazione dei modelli di giustiza costituzionale. Torino: Giappichelli.

Chinchón Álvarez, J. (2014). Jurisdicción universal. Eunomia. Revista en Cultura de la Legalidad, 7, 234-246. Disponible en: https://bit.ly/2WKesix.

Colombo, I. (2019). El margen de apreciación nacional y su marco teórico. Comunicación presentada al XIV Congreso Iberoamericano de Derecho Constitucional: "La Democracia Constitucional en América Latina: a 45 años del Instituto Iberoamericano de Derecho Constitucional y a 40 años de la Asociación Argentina de Derecho Constitucional». Disponible en: https://bit.ly/2WNFKou. 
De Vega García, P. (2002). La eficacia frente a particulares de los Derechos Fundamentales (la problemática de la Drittwirkung der Grundechte). En M. Carbonell (coord.). Derechos Fundamentales y Estado. Memoria del VII Congreso Iberoamericano de Derecho Constitucional. México: Universidad Nacional Autónoma de México.

Fondevila Marón, M. (2017). Control de convencionalidad y tutela multinivel de derechos. Estudios de Deusto, 65 (1), 347-360. Disponible en: https://bit.ly/ 2Q1Lv0f.

Jimena Quesada, L. (2013). Jurisdicción nacional y control de convencionalidad. A propósito del diálogo judicial global y de la tutela multinivel de derechos. Navarra: Thompson Reuters.

- (2019). La consagración del control de convencionalidad por la jurisdicción constitucional en España y su impacto en materia de derechos socio-laborales (comentario a la STC 140/2018, de 20 de diciembre). Revista General del Derecho del Trabajo y la Seguridad Social, 53, 435-461.

Kelsen, H. (1981). La giustiza costituzionale. Milano: Giufffrè.

López Guerra, L. (2019). Convencionalidad y Constitucionalidad. Los casos de México y España. Boletin Mexicano de Derecho Comparado, 43-64. Disponible en: http://dx.doi.org/10.22201/iij.24484873e.2019.153.13258.

Llobret Anglí, M. (2006). El alcance del principio de jurisdicción universal según el Tribunal Constitucional. Una discutible interpretación de la STS de 20 de junio de 2006. Indret, 4. Disponible en: https://bit.ly/2PUbbvX.

Matia Portilla, F. J. (2016). Las tensas relaciones entre el Tribunal Supremo y el Tribunal Constitucional y los límites de la (legítima) discrepancia entre ellos. Revista de Derecho Político, 97, 11-48. Disponible en: https://bit.ly/33iw085.

Mirkine-Guetzévitch, B. (2008). Derecho Constitucional Internacional. Madrid: Reus.

Nogueira Alcalá, H. (2012). Los desafíos del control de convencionalidad del corpus iuris interamericano para las jurisdicciones nacionales. Boletín Mexicano de Derecho Comparado, 135, 1167-1210.

Nuevo López, P. (2015). Control de convencionalidad y aplicación judicial de los Derechos Fundamentales de la Unión Europea. Revista Catalana de Dret Públic, 50, 141-160. Disponible en: http://dx.doi.org/10.2436/20.8030.01.48.

Pegoraro, L. (2015). Giustiza costituzionale comparata. Dai modelli ai sistemi. Torino: Giappichelli.

Queralt Jiménez, A. (2018). Las sentencias piloto como ejemplo paradigmático de la transformación del Tribunal Europeo de Derechos Humanos. Teoría y Realidad Constitucional, 42, 395-424.

Ruipérez Alamillo, J. (2017). La necesidad de constitucionalizar como "fundamentales» algunos derechos atinentes a la dignidad de la persona. El derecho a una vivienda digna. Santiago de Compostela: Andavira.

Sagüés, P. N. (2011). Control de constitucionalidad y control de convencionalidad a propósito de la «constitución convencionalizada». Parlamento y Constitución, 14, 143-152. Disponible en: https://bit.ly/2PMW47i. 
- (2014). Nuevas fronteras del control de convencionalidad: el reciclaje del derecho nacional y el control legisferante de convencionalidad. Revista de Investigaçoes Constitucionais, 1-2, 23-32. Disponible en: http://dx.doi.org/10.5380/ rinc.v1i2.40509.

Salcedo Beltrán, M. ${ }^{a}$ C. (2014). Jurisprudencia del Comité Europeo de Derechos Sociales y período de prueba del Contrato de Apoyo a Emprendedores: la aplicación del control de convencionalidad en España. Lex Social, Revista jurídica de los derechos sociales, 4 (2). Disponible en: https://bit.ly/2PLwWxF.

Sánchez Legido, A. (2014). El fin del modelo español de jurisdicción universal. Revista electrónica de estudios internacionales (REEI), 27, 40 págs. Disponible en: https://bit.ly/2PQ7046.

Tenorio Sánchez, P. J. (2018). ¿Qué fue del recurso de amparo ante el Tribunal Constitucional? Revista de Derecho Político, 101, 703-740. Disponible en: https:// bit.ly/2oPbX27. 